\title{
Los fantasmas de la colonialidad en el Mundo moderno contemporáneo ${ }^{1}$
}

The ghosts of coloniality in the contemporary modern world

\section{MEJÍA NAVARRETE, Julio²}

Resumen: El texto describe el desarrollo de una tendencia contemporánea de la modernidad, de la colonialidad, de su lado oscuro. Fantasmas de la colonialidad que anuncian un mundo deshumanizado. Cuestiones que abren caminos marcados por la precarización laboral, inferiorización de las mayorías y el advenimiento de un nuevo conflicto xenófobo-racial, que envuelven la propagación de un proyecto global de barbarie cultural y de un régimen político segregacionista.

Palabras-clave: Colonialidad del poder. Precariedad. Conflicto xenófobo-racial. Proyecto de barbarie cultural y régimen político segregacionista.

\begin{abstract}
The text describes the development of a contemporary trend of modernity, of coloniality, of its dark side. Ghosts of coloniality that announce a dehumanized world. Issues that open paths marked by labor precariousness, inferiority of majorities and the advent of a new xenophobic-racial conflict, which involve the spread of a global project of cultural barbarism and a segregationist political regime.
\end{abstract}

Keywords: Coloniality of power. Precariousness. Xenophobic-racial conflicto. Project of cultural barbarism and segregationist political regime.

\footnotetext{
${ }^{1}$ Autor convidado para esta ediçãoda REALIS.

2 Doctor en Ciencia Política y Sociología por la Universidad Pontificia de Salamanca, 1994. Docente titular y actualmente Decano de la Facultad de Ciencias Sociales de la Universidad Nacional Mayor de San Marcos. Coordinador de la Cátedra América Latina y la Colonialidad del Poder de la Universidad Ricardo Palma. Miembro del Grupo de Trabajo Violencia y Ciudadanía del Consejo Latinoamericano de Ciencias Sociales (CLACSO). Coordinador del Doctorado de Ciencias Sociales de la Universidad Nacional Mayor de San Marcos. Email: jvmena1@hotmail.com
} 
El artículo examina las implicancias de la colonialidad en el mundo contemporáneo. Destaca el examen de los principales acontecimientos sociales del siglo XXI a partir de la perspectiva teórica de la colonialidad del poder. Antes que presentar un cuadro de evolución de las ideas, importa confrontar la perspectiva de la colonialidad como una matriz conceptual fundamental que posibilite comprender las tendencias centrales de la sociedad moderna global.

La colonialidad en el mundo contemporáneo se expresa claramente en la transformación raigal del sistema moderno que tiende a considerar a sectores importantes de la población como seres inferiores, con la extensión de la precariedad, la informalidad, hasta el desarrollo de formas esclavizadas $\mathrm{y}$, paralelamente, trae la agitación de un nuevo conflicto xenófobo-racista, que envuelven la propagación de un proyecto global de barbarie cultural y de un régimen político segregacionista.

El texto describe el desarrollo de una tendencia de la modernidad, de la colonialidad, de su lado más oscuro. Lado oscuro que circunda cada vez más a la existencia contemporánea, fantasmas de la colonialidad que anuncian un mundo deshumanizado. Conocerlo es también una posibilidad reflexiva de adelantarse a su historicidad, para buscar otros caminos más dignos del discurrir de la vida social.

Aquí se analizan las amenazas de la colonialidad en la modernidad global, para ello se formulan algunas hipótesis iniciales que faciliten estructurar un debate mayor. Las respuestas y movimientos de la sociedad son abordados en otros textos (Mejía 2016 y 2019).

\section{1. modernidad y colonialidad global}

La modernidad global neoliberal se encuentra en una gran encrucificada, sin precedentes históricos, presionada por la crecimiento exponencial de la desigualdad social, la precarización laboral y la inferiorización de las poblaciones.

Precisamente, la modernidad como organización de la sociedad mundial, no es entendida como una forma exclusivamente europea, tuvo su origen en la conquista del 
nuevo mundo en el siglo XV. Resultado de un proceso simultáneo entre Europa y América, en el que concurren los mismos hechos históricos de conformación de un patron de poder que califica ante todo los beneficios mercantiles, luego las vidas de los seres humanos. Justamente, la sociedad moderna integra dos aspectos centrales que definen su desarrollo universal, un estructura de explotación social fundada en la hegemonía del capital y una insólita organización de dominación basada en la inferiorización racializada de la población. Modernidad y colonialidad son aspectos complementarios de una misma dinámica global ${ }^{3}$.

Walter Benjamim $(1967,46)$ lo expone claramente "no existe documento moderno de cultura que no sea a la vez documento de barbarie". Efectivamente, por un lado, el patrón moderno significa el desarrollo exponencial de la vida urbana, la ciencia, la tecnología, el trabajo asalariado, el crecimiento económico y social. Al mismo tiempo, conlleva su aspecto más oscuro, la extensión de la polarización extrema en el mundo, las mayoría de personas son sometidas e inferiorizadas, se les cuestiona su humanidad y se transforma en barbaros "diferentes por naturaleza", en seres poco humanos. En ese sentido, la racialización, no solo tiene que ver con el color de piel, es esencialmente la capacidad de control del pensamiento de las gentes, de clasificación social, para poder dominarlos hay que inferiorizarlos, porque no se puede someter y dominar a los iguales. La modernidad establece una organización de la sociedad que hace la "vida humana desechable" para la mayoría de las gentes de la tierra, porque las transforman en objetos mercantilizados para ser explotados y dominados para el interés del capital (Mignolo 2006).

Ciertamente, con la conquista de América Latina y el desarrollo de la periferia del mundo se perfila la hegemonía de la colonialidad, como el eje central de la relaciones de poder y la mayoría de sus poblaciones son transformadas en parias, indígenas, negros o mestizos desprovistos de todos sus derechos, a lo que es necesario civilizar para lo cual hay que someterlos o en caso de resistencia aniquilar. Frantz Fanon

\footnotetext{
${ }^{3}$ Una discusión amplia puede consultarse Aníbal Quijano (2014), Mignolo (2003), Mejía (2014, 2019). Germaná (2010, 2019), Palermo y Quintero (2014) y Assis Clímaco (2014).
} 
(2001 [1961]) los considerada como zonas del no-ser planetario por ser habitadas por personas racialmente inferiores, por los condenados de la tierra, la dominación pasa por el predominio del “apropiación/violencia”, la ciudadanía con derechos sociales se reduce a una capa minoritaría cercana al poder. En forma contraria, los países metropolitanos de Europa y EEUU tendían a organizar sus sociedades por el capital y las relaciones asalariadas, el Estado se volvía nacional y la colonialidad se reducía a los márgenes de la sociedad, a la población negra e india en los Estados Unidos o a grupos étnicos subordinados de romaníes, judíos y otros en Europa. Es la zona del ser, la ciudadanía se expandía a sectores importantes de la población, tienen derechos reconocidos y los conflictos se deciden por la "regulación/emancipación" (Santos 2010, 20-23). De esa manera, en el mundo moderno las formas de entereza de la vida y la ciudadanía tienen como condición de posibilidad la destrucción y colonialidad mayoritaria de la vida de los otros. Los afortunados de la tierra viven a costa de los condenados de la tierra.

Vinculado a lo anterior, a partir de las últimas décadas del siglo XX opera un proceso de revolución de la automatización y de la inteligencia artificial en los procesos productivos y reorganización del trabajo, modificando drásticamente el sistema moderno al limitar la producción del trabajo asalariado masivo, lo paradójico es que ocurre cuando se produce más empleo y riqueza que en cualquier otro momento de la historia (Standing 2016). Replanteando que la reproducción del patrón moderno capitalista discurra más por caminos de la precarización laboral, el desempleo estructural, la amplificación de la pequeña producción mercantil y de formas que se acercan a relaciones esclavistas y serviles. El resultado de la modernización neoliberal es la brutal concentración de riquezas y recursos que llevan a la desigualdad social extrema (Piketty 2015).

¿Qué esta ocurriendo?. Estamos frente a una tendencia mundial sin precedentes de precarización e inferiorización de las poblaciones (Touraine 2016, 46). La dinámica del patrón moderno globalizado se expande en función principalmente de la precariedad, desempleo estructural y del trabajo forzado, lo cual solo puede hacerlo recurriendo a la clasificación como seres inferiores o convertidos en cosas y remanentes que se puede excluir fácilmente (Standing 2013). El desarrollo de la modernización neoliberal tiende a generalizar la colonialidad de sus poblaciones, son transformados en individuos superfluos, sin posibilidades de (re)incorporarse a la fuerza laboral y al consumo, son los 
nuevos pobres, no por estar sin trabajo sino, principalmente, porque son los expulsados del mercado dominante (Bauman 2000). Se desarrolla una cultura que le substrae el "rostro" al otro, para despojarlo de todos los elementos de su identidad excepto el ser marginados, expropiando sus facultades morales que los convierte en seres indignos, humillados y privados de los derechos para poder revertir su humanidad. La modernidad global elabora una cultura sobre la división extrema de la sociedad, que alude a una forma de diferenciación ontológica del ser, al otro le corresponde la exclusión por la carencia de identidad con el trabajo asalariado, el consumo y todo tipo de derechos humanos, únicamente le corresponde la imagen peyorativa de un ser disfuncional e inferiorizado (Mejía 2016, 320).

En la actualidad, el mundo ha entrado a una etapa de mayores desigualdades de su historia. La relación entre el norte desarrollado y el sur atrasado expresan una división en términos epistemológicos, ya no corresponde más a una connotación geográfica y social. La globalización neoliberal forja una creciente diferenciación social al interior de todos los países, la precarización e inferiorización de la población se expande de modo creciente, la ciudadanía retrocede va perdiendo derechos, la injusticia y la violencia se apropian de los resortes de la vida cotidiana, el Estado se transforma cada vez en una entidad excluyente y traduce una imposición mayor del capital monopólico internacional. Todas las naciones del planeta desarrollan espacios del norte global con élites muy ricas y semejantes y su contraparte del sur global habitado por los excluidos, los negados, los "condenados de la tierra", donde predomina el precariado y la inferiorización racializada de las poblaciones.

Transformación profunda de la existencia social moderna que induce al agotamiento de la idea del futuro como promesa y se reemplaza por la figura de una historia futura profundamente dominada por la precariedad, desigualdad y exclusión, directamente relacionada con la amenaza y el riesgo (Beck 1997), de la colonialidad global.

\section{Nuevo conflicto xenófobo-racial global}


En los últimos tiempos la sociedad moderna acarrea otras formas de colonialidad que refieren un nuevo "horizonte xenófobo-racial" conflictivo a partir del enfrentamiento y rechazo que despiertan la persistente inmigración económica internacional, la presión de los refugiados y el retorno de las viejas minorías étnico-religiosas (Castells 2018a).

En efecto, el escenario actual describe un nuevo conflicto xenófobo-racial, en parte, moldeado por las oleadas de inmigrantes económicos de las naciones de América Latina, África y del tercer mundo a los países más desarrollados. La migración internacional en los últimos 40 años se estima en alrededor de 200 millones de personas que han pretendido trasponer las fronteras de los países de forma no documentada (OIT 2013). Es un fenómeno de repercusión social y política fundamental en el sistema global moderno, debido a las trabas fronterizas nacionales que prohíben la libre circulación de personas, paradójicamente en momentos de apertura a los mercados mundiales de productos. Sin embargo, siempre la población del mundo pobre encuentra variedades de formas para movilizarse constantemente a los países de Estados Unidos y Europa, despertando oposiciones y rencores étnicos-raciales en núcleos importantes de las fuerzas ultranacionalistas de derecha.

Inmigrantes económicos que impactan significativamente en el desarrollo de un nuevo horizonte xenófobo-racista. En los últimos años Estados Unidos se ha visto alterado principalmente por las corrientes migratorias económicas del Triángulo Norte de Centroamérica -Guatemala, Honduras, El Salvador-, que discurren por México como país de tránsito, se proyecta para el año 2019 hasta 1.072.000 detenciones en su frontera sudoccidental (Jalife 2019a). El resultado de este proceso, es la reacción de rechazo étnico-racial del 'bloque antimigratorio' proclive al Partido Republicano y al supremacismo blanco -WASP- White AngloSaxon Protestant (Jalife, 2019a), que clasifican en el nivel inferior a los inmigrantes provenientes de los "países letrina" de América Latina, África y del Tercer mundo.

En Europa la situación es igual de grave, a sus problemas tradicionales se suma las consecuencias de la desestabilización y la guerra provocada en Siria, Irak, Libia y el Medio Oriente por los EEUU, siempre con apoyo de la Unión Europea. Aquí la inmigración tiene una connotación de poblaciones que buscan refugio, huyen de la guerra civil y de las 
invasiones extranjeras de sus países, produciendo el desplazamiento de 10 millones de personas (Collier 2018, 341) que ha forjado alrededor de 2 millones de refugiados en el viejo continente. Frente a ello, la reacción es virulenta de los partidos de derecha "populistas", neofascistas y de los gobiernos ultranacionalistas y racistas antimigratorios como el de Salvine en Italia y los de Europa del Este.

También, reaparece la agitación de la vieja diversidad europea de minorías étnicas, identidades y de grupos religiosos en Europa y los Estados Unidos que coadyuvan a la gestación del novísimo conflicto xenófobo-racial global. Basta citar los temores étnicosraciales que despiertan en la Unión Europa los 25 millones de ciudadanos residentes de origen musulmán; igualmente regresan con fuerza antiguas identidades nacionales que azuzan graves inestabilidades como la catalana, la escocesa, del País vasco, Gales, Flandes, etc. (Castells 2018b, 274); la confrontación y rechazo judío vuelve agitarse desde 1980 en determinados sectores juveniles, en particular de Europa central (Wieviorka 2018, 317); y, agudizando más el horizonte conflictivo étnico, se desatan temores ante el propio desplazamiento de las poblaciones del Este y del Sur europeo a los países más industrializados Inglaterra y Alemania. Procesos que los Estado-nación no han podido resolver, destacamos la experiencia truncas de Gran Bretaña, España y el "Estado red" de la Unión Europea. En esa misma dirección, las fracturas xenófoba-raciales empiezan ha reaparecer en los Estado Unidos, que hacen referencia a un problema que adquiere ribetes alarmantes, la población de origen blanca representa el 62\%, frente al 18\% de los latinos, donde el $80 \%$ son migrantes mexicanos, que por sus altas tasas de natalidad en una generación, para el 2050, podrían convertirse en el principal grupo étnico del país del norte (Jalife 2017), situación que ha llevado que el estado de California, uno de los más importantes y ricos de la unión Americana tenga una población mayoritariamente de migrantes mexicanos.

Esta situación conflictiva, ha despertado los ancestrales fantasmas antiétnicos y raciales de Europa y EEUU propiciando el surgimiento de los "populismos" y neofascismos. El Presidente Donald Trump lo expresa claramente en su discurso de odio racista y misógino, en particular contra las ciudadanas estadunidenses no blancas, de origen latino, somalí, afroamericano o asiático, y enfatiza su expulsión de cada una de ellas: "Send her back" -“Énviela de vuelta" - (Rosas 2019, 16). 
La diversidad cultural de las sociedades modernas y los actuales intereses globalizados, con serios vacíos institucionales en los países, están agudizando una nueva dinámica de colonialidad xenófoba-racial en la que concurren las viejas heridas de diferenciación de las minorías que se combinan con las nuevas formas de discriminación que asoman frente a la inmigración y los refugiados, que pueden llevar que Europa y los Estados Unidos se transformen en espacios de "aglomeración de archipiélagos étnicos entrecruzados y superpuestos" (Bauman 2013, 74).

\section{Momento populista}

La colonialidad se ha transformado en una cuestión esencial de la dinámica moderna contemporánea. Fracturas de la modernidad que conlleva el desarrollo histórico de un "momento" populista (Laclau 2006, 32-33), que por su carácter envuelven la crisis de la democracia liberal y la gestación principalente de formas políticas "populistas" y neofascistas.

El mundo se encuentra en una situación caótica, después de la caída del muro de Berlín y del desmoronamiento del socialismo realmente existente, se apertura una historicidad compleja cuyas consecuencias van ha signar el rumbo del mundo de las próximas décadas. De la bipolaridad EEUU-URSS se pasó a la hegemonía norteamericana, hasta llegar al siglo XXI de disputa intensa entre superpotencias, con la emergencia económica de China y el poderío militar de Rusia.

En ese contexto, asistimos a una crisis de la democracia liberal, definido por la aguda desconfianza y pérdida de legitimidad de sus instituciones, las dos terceras partes de los ciudadanos del mundo occidental consideran que esta forma de gobierno no los representa y solo sirven a intereses privados (Castells 2017a,18). Aunque siempre existieron, quizás sea la corrupción y la economía criminal, violencia y narcotráfico las amenazas más serias, según los países, ahora convertidas en influencias desestabilizadoras del sistema. Situación crítica que posibilita la aparición de formas que controvierten directamente el régimen de democracia liberal. El desarrollo de regímenes 
no democráticos en China y Rusia cobran una legitimidad cada vez mayor en el mundo, dada su pretendida eficacia para resolver los graves problemas que afectan a las naciones. Por otro lado, lo más duro del cuestionamiento de la democracia liberal es la formación de gobiernos y partidos ultranacionalistas "populistas" y neofascistas en Europa y América, vasta citar la elección de Donald Trump en EE UU, Matteo Salvini en Italia y, recientemente, de Bolsonaro en Brasil.

Quizás la explicación se encuentre en el desarrollo de un momento populista o, mejor dicho, coyuntura histórica donde se pone en jaque la hegemonía del régimen político desplegado por la globalización neoliberal desde fines del siglo pasado y comienzos del presente, aquel que tuvo su experimento con la dictadura de Pinochet en Chile de 1973 y Fujimori en el Perú de 1990, consolidándose con la elección de Margaret Thatcher en1979 y de Ronald Reagan en 1980 y, luego, para expandirse por todo el mundo.

Coyuntura "populista" que tiene sus antecedentes históricos en el régimen político de fines del siglo XIX e inicios del XX, denominado por Lenin (1977 [1917]) como la era de los monopolios capitalistas, que llevó a la gran crisis de los años treinta y la Segunda Guerra Mundial, examinado para el caso peruano su desarrollo por Peter Klaren (1976) y su dinámica de crisis por Tirso Molinari (2017). Coyuntura histórica "populista" que describe situaciones temporales semejantes, aunque disímiles socialmente, frente a la concentración del capital que implicaba la formación del capitalismo monopólico a fines del siglo XIX, aquí es cuando aparece el término "populista" en Rusia con la experiencia Narodnaya Volia, presionados por la urgencia de la modernidad y el despotismo zarista, y más claramente en los Estados Unidos con la protestas de los farmers y en la constitución del Peoples's party en 1890. Por otro lado, el término "populista" se desarrolla con la crisis del treinta, la segunda Guerra Mundial hasta los años setenta, dominado por la derrota nazifascista y la irrupción de las luchas nacional-democrático-popular, que recogían la incorporación de los derechos sociales de asalariados y de indios, negros, mestizos y mujeres, se propugnaba la ampliación de los niveles de ciudadanía, tuvo sus predecesores en la revolución mexicana y llevó a regímenes desde Perón en Argentina hasta Velasco Alvarado en el Perú (Quijano 1998, 171-205). Esta forma de populismo insistía en la 
democratización de la sociedad y la ampliación de la ciudadanía nacional popular, en especial de América Latina (Lynch 2017).

La presente coyuntura histórica "populista" consiste en que las masas ya no se reconocen en el régimen político neoliberal y se movilizan contra las élites globalizadas que precarizan la vida social, abriéndose a una diversidad de fuerzas políticas. Confluyen en una "coalición populista" determinados sectores sociales afectados por la concentración del capital, en la actualidad por los capitalistas globales y las "elites cosmopolitas de las grandes ciudades": burguesías locales del interior de los países, capas medias y "clase obrera blanca (hombres y mujeres) y población rural" sin mayores estudios (Castells 2017b). En este escenario, se cristaliza el predominio de aquellas propuestas abiertamente ultranacionalista, de odio racista, capitalista y liberal, y, en esa dirección, baten intensamente una promesa de establecimiento de un régimen político despótico con fachada democrática.

Aquí, destaca la insurgencia de las masas populares, ahora más desintegradas socialmente y desmontadas en sus organizaciones. Bauman (2016, 165-169) denomina precariado, al proceso que afecta y genera el debilitamiento de las capas medias y asalariados por la expansión de la precariedad laboral, exclusión, segregación espacial e inferiorización social. Fuerzas heterogéneas que conjugan un amplio proceso de oposiciones y movimientos de la sociedad que cuestionan significativamente a las élites globales (Cardoso et al 2018, Mejía 2019).

En dicho escenario "populista" aparecen un conjunto de nuevos liderazgos y partidos políticos que pugnan por conquistar a las masas populares precarizadas. Inciden los intentos de recuperación de los viejos partidos socialdemócratas, son conocidas las experiencias de España, Portugal y Suecia, que apelan a alianzas con la izquierda, la defensa del Estado de bienestar y al desarrollo de la cultura feminista y ecológica; también aparecen expresiones novísimas de fuerzas democrático-popular como Podemos en España y SYRIZA en Grecia situados en la oposición del pueblo contra las élites globales, recogen la propuestas de los derechos de la mujer, gays y lesbianas, de los inmigrantes, de la defensa de la naturaleza y, en general, los derechos humanos, proponen la reconstrucción del Estado de bienestar y la defensa de la patria frente al capitalismo 
global neoliberal (Castells 2018c, 506-507). Sobre todo, irrumpen las fuerzas de extrema derecha que se extiende a todos los países de Europa y América, con manifestaciones autoritarias y de encono racial en los "partidos xenófobos y ultranacionalistas" (Castells 2019), opuestos a toda forma de inmigración, en especial, de rechazo a los refugiados, se enfrentan a cualquier poder supranacional o de la Unión Europea, siempre apuestan por una mayor mercantilización de la naturaleza y están dispuestos a arroyar cualquier forma de derechos humanos, destacando las expresiones iniciales del "populismo neoliberal" como el de Fujimori y Menen en los noventa (Quijano 1998), el nacional-populismo del Frente Nacional de Jean-Marie Le Pen (Wieviorka 2018) y la insurgencia grupos cercanos al fascismo como el de Matteo Salvini (Castells 2018a), Amanecer Dorado en Grecia o el Ku Klux Klan en Estados Unidos. Grupos que presionan al propio gobierno como en Italia, EEUU, Brasil, Austria o Hungría, con partidos políticos de ultraderecha en Alemania, Finlandia, Noruega, y su desarrollo en países tradicionalmente tolerantes como Holanda, Dinamarca o Suecia.

Momento "populista" cuya transición parece inclinarse, principalmente, por la crisis de la democracia liberal y la aparición de fuerzas inusitadas de los partidos populistas y neofascistas que agitan fantasmas de la colonialidad xenófobo-racista.

\section{Proyecto global de "barbarie cultural" y de un régimen político de apartheid}

La extensión creciente de la colonialidad esta llevando a un proceso de la relegitimación del discurso racista y la irrupción del proyecto global de segregación de la población mundial.

En los últimos años arremete con mucha intensidad el "proyecto" de "barbarie cultural" para manipular las "mentes y las emociones" (Castells 2019) con contenidos comunicativos que ponen en cuestión la humanidad de sectores importantes de la población del planeta: racialización, xenofobia, antiétnico, antirreligioso, antimigratorio, misógino, odio a la democracia y a favor de toda forma inferiorización. Hacen uso intensivamente de los medios y redes sociales a través de la "comercialización del sensacionalismo y el espectáculo del miedo" (Castells 2014, 5), con la intención explicita 
de propiciar un imaginario contrario a los derechos humanos, de irrespeto a las libertades y la deconstrucción de instituciones democráticas, en particular de la educación y las universidades, para buscar crear ciudadanos poco educados, mal informados y sumisos (Castells 2019). Narrativas que se agitan y difunden en la escena internacional, impulsado por los grupos y partidos de extrema derecha para instalar el reconocimiento de un pensamiento xenófobo-racista que traduce "la negación de los derechos humanos a ciertos humanos mediante la violencia del Estado" (Castells 2018a).

Proceso de relegitimación del imaginario xenófobo-racista que tiene su punto de mayor inflexión con la llegada de Donald Trump a la Presidencia de los Estados Unidos el 20 de enero de 2017, representando "un modelo" y "una fuente de convalidación" para todo el mundo (Finchelstein 2019, 257), flamenado un discurso de supremacía blanca y opuesto a los inmigrantes latinos, mexicanos, la población negra y, partir de ahí, contra las mujeres, homosexuales y la devastación de la naturaleza. Justamente, el momento presente conlleva el desarrollo de una episteme violenta que modifica radicalmente el periodo anterior, abierto con la derrota de los nazi-fascismos después de la segunda guerra mundial que llevaron a la crisis y deslegitimación del discurso racial, asociado a la expansión de los movimientos por los derechos civiles, la descolonización del Tercer Mundo y la toma de conciencia a los horrores del Holocausto.

¿Por qué? la arenga racial nuevamente se incorpora a la proclama violentista desde el Estado, se vuelve a instalar directamente en la esfera del poder y se transforma en uno de los mayores peligros para la humanidad. Discurso cuyo contenido ideológico niega la humanidad de grupos importantes de la población y apela a la violencia permanente, impugna descaradamente la legitimidad de la igualdad social para argüir cínicamente a favor de la concentración de la riqueza, recursos y del poder por la élite del capital globalizado, y azuza provocadoramente el desarrollo de un régimen político despótico como aspecto central de la organización de la vida social, siguiendo las experiencias del Asia, donde la democracia se vuelve más una portada que realidad.

La racialidad se encuentra en un claro proceso de expansión que tiñe a la modernidad global actual como una de sus características mayores. Donald Trump fundamenta su presidencia y la política de la primera potencia mundial en la provocación 
del odio xenófobo-racial. Igualmente, se expresa cuando el Ministro del Interior de Italia Matteo Salvini denomina "carne humana" a los refugiados del mar; Hungría aprueba leyes que codena a los que ayuden a los inmigrantes indocumentados, mentalidad que se extiende al rechazo de los inmigrantes de Europa pobre en el Reino Unido como lo "demostró el Brexit" (Castells 2018a); y en Brasil cuando el Presidente Bolsonaro reclama el exterminio de los indígenas, se muestra abiertamente racista, homofóbico y misógino. Asistimos, sin tapujos, a la instalación paulatina en el mundo de una narración de inferiorización racial de sectores importantes de la población mundial.

Por otra parte, en condiciones de inferiorización racializada de sectores importantes de la población mundial, relegitimación de un horizonte xenófobo-racista y crisis de la democracia liberal, pareciera que recibe un empuje el proyecto a nivel global de un régimen político de apartheid apuntalado por las fuerzas de extrema derecha, de los grupos populistas y neofascitas. Proyecto de régimen político que no tiene porqué llamarnos de sorpresa, viene ocurriendo en el Estado de Israel desde 1948 contra las poblaciones palestinas y tuvo su origen en el Regimen de Sudáfrica de 1948 - 1990. Naciones Unidas en diciembre 2017 dictaminó, por medio de la Comisión Económica y Social para Asia Occidental, que Israel es un régimen político de apartheid ${ }^{4}$.

El proyecto global de apartheid aparece en el escenario como un régimen político que propugna sustancialmente un "desarrollo separado" y segmentado de las poblaciones dominadas, implica la división territorial segregada del Estado y recurre a una clasificación étnica-racial, que posibilitan subyugar a determinados grupos inferiorizados de indios, negros, mestizos, palestinos, inmigrantes, refugiados, de religiones otras, etnías, en favor de los sectores minoritarios hegemónicos de la modernidad del siglo XXI (Tazon 2008). Sin embargo, pareciera que este regimen político segregacionista encierra la mezcla nefasta entre las fronteras "fortalezas" y la necesidad de contar con una mano de obra barata para realizar los peores trabajos y en las condiciones de mayor dominación,

\footnotetext{
${ }^{4}$ La tercera sesión del Tribunal Russell (2011) sobre Palestina, un tribunal ético creado por el reiterado fracaso de los gobiernos para obligar a Israel a cumplir las resoluciones de la ONU, concluyó que el régimen impuesto sobre la población palestina se ajusta a la definición jurídica de apartheid.
} 
a la modernidad del siglo XXI no interesa si la muerte aparece o las personas se deshumanizan (Bauman 2008, 54).

Proyecto que no significa un inacabable devenir histórico, más bien se conforma de fragmentos institucionales, a veces aislados, y de formas cínicas en su polo más desarrollado. En efecto, desde 1948 el Estado de Israel instaura en forma abierta el apartheid contra las poblaciones de la antigua Palestina. A las gentes de Palestina se le consignan espacios territoriales como campos de concentración y organiza un verdadero "desarrollo separado" con barreras físicas en forma de muros, donde se controla el tránsito, la movilidad y se recrean las viejas condiciones de clasificación racistas y etnicas. Lo grave es que el Estado de Israel y el régimen político de apartheid fue tolerado y permitido por las potencias hegemónicas de la modernidad global.

Asimismo, las migraciones internacionales vienen constituyéndose en los espacios de apartheid más críticos del mundo globalizado, la respuesta inmediata de algunos países es una política segregacionista de la edificación de muros, lo formuló desvergonzadamente el twitter de Donald Trump5: "hay 77 grandes o importantes muros construidos en todo el mundo; hay 45 países que están planificando o construyendo muros". Un punto neurálgico de muros y vallas es la frontera de EuropaÁfrica, las costas del Magreb se han configurado una de los grandes áreas de detención, retención y reclusión de poblaciones de los países pobres, impedidos de entrar o cuando lo hacen se transforman en los nuevos parias de la colonialidad en la modernidad del siglo XXI. Paradójicamente, en "Europa Fortaleza" después del derribo del muro de Berlín se han construido más 1000 km, habían dos en los noventa y en la actualidad su número aumentó a 15, lo han edificado diez países de los 28 miembros y, en particular, para impedir la llegada de refugiados y reprimir la inmigración de Oriente Medio se han construido descaradamente en Austria, Eslovenia, Hungría, Macedonia, Bulgaria y Grecia (Ruiz y Brunet 2018). Otro punto

\footnotetext{
5 El twitter de Donald Trump del 16 de enero 2019: "There are now 77 major or significant Walls built around the world, with 45 countries planning or building Walls. Over 800 miles of Walls have been built in Europe since only 2015. They have all been recognized as close to $100 \%$ successful. Stop the crime at our Southern Border!"
} 
central es la frontera sur mexicana, que controla la entrada de América Latina a Estados Unidos. Sin embargo, pareciera que lo más importante es la similitud del "muro Trump" de rechazo y la "palestinización de los mexicanos" con el "supremacismo racista/paria/apartheid del premier israelí Netanyahu". Política efectivizada en el proyecto del muro en la frontera de México, de modo particular, para impedir que el Estado de Texas se convierta en una población de mayoría latino-mexicana y el mismo sería edificado por una empresa especializada israelita (Jalife 2019b).

Del mismo modo, este régimen de segregación se expresa crecientemente en el desarrollo de las ciudades del mundo moderno neoliberal, los muros y enrrejados tienden a separar a las urbanizaciones de lujo, condominios, clubs sociales privados y balnearios exclusivos de las élites del resto de los habitantes, definen su estructura urbanística en una "comunidad planificada con verjas, puertas y guardias, como si esta fuera la imagen de la buena vida" (Sennett 1997, 23). Las ciudades estan transformadose en espacios de inseguridad, donde circulan el desempleo, la precariedad, la informalidad, la inmigración, la discrimnación étnica-racial y la criminalidad. La ciudad tiende a redefinirse en función de la fractura de la colonialidad, del miedo frente a la precariedad de las gentes, degradación urbanística y la violencia, el resultado es la emergencia de un régimen fragmentado y dividido socioespacialmente, en la que coexiste con la exclusión y marginación de amplios sectores por el desarrollo de las grandes desigualdades sociales. La existencia urbana se erige esencialmente en función de la distancia, diferencia, discriminación y segregación social, se trata de la hegemonía de una estructura de colectividades cerradas, en la que se combina "espacio y subjetividad" (Jones, 2013). La ciudad muestra que el régimen político de apartheid no es transicional sino viene a ser la forma despótica de cómo se organiza la vida social en el siglo XXI.

Proyecto de régimen de apartheid que se instala y se relegitima desde el Estado y simboliza el otro aspecto de la sociedad global neoliberal, la inferiorización racializada de la población, sometida a la violencia, negación de sus derecho y ser explotada en las peores condiciones sociales. 


\section{Comentarios finales}

Los fantasmas de la colonialidad recorren el mundo contemporáneo, se han transformado en las amenazas más seria y pueden trazar un camino que podría llevarnos al infierno de la vida social. El devenir que bosqueja la modernidad se encuentra cada vez más constituida por la colonialidad.

Cuestiones que abren caminos marcados por la precarización laboral, inferiorización de las mayorías y el advenimiento de un nuevo conflicto xenófobo-racial, procesos que involucran la crisis de la democracia liberal, la emergencia de un mensaje de barbarie cultural y el desarrollo de la propuesta global de un régimen político segregacionista. Etapa histórica del patrón moderno mundial que bifurca un conjunto de direccionalidades cuyas consecuencias son críticas para la humanidad.

Quizás, todo ello tenga que ver con el carácter que asume la modernidad en la globalización neoliberal, que ha llegado a su nivel de mayor reconcentración del control de los recursos y del poder mundial, acarreando drásticamente la reconfiguración despótica de la estructura institucional y el desarrollo de una clasificación social que amenaza a la población mundial. Lo peor de todo, es que la colonialidad se empeña en aparecer en la forma más cínica como un hecho naturalizado que sobrepasa a las facultades humanas.

Transformaciones profundas de la modernidad contemporánea que inducen al colapso de los grandes logros que trazó en su origen el modernismo, de libertad, igualdad social, condiciones que apertura un camino de colonialidad y niega la esperanza de erradicar la miseria del destino humano.

En general, en una realidad social dominada por la colonialidad buscar otros caminos es apegarnos a lo último que queda invocando valores de dignidad humana, de sueños de justicia social contra la destrucción y el sufrimiento. 


\section{Bibliografía}

ASSIS CLÍMACO, D. (2014): “Selección y Prólogo”. Aníbal Quijano: Cuestiones y horizontes: De la dependencia histórico-estructural a la colonialidad/descolonialidad del poder. CLACSO: Buenos Aires.

BAUMAN, Z. y BORDONI C. (2016). Estado de crisis, Paidós: Bogotá.

BAUMAN, Z. (2013): La cultura en el mundo de la modernidad líquida. FCE: México.

BAUMAN, Z. (2008): Archipiélago de excepciones. Katz: Barcelona.Bauman, Z. (2000). Trabajo, consumismo y nuevos pobres. Gedisa: Barcelona.

BECK, U. (1997). La sociedad del riesgo mundial: en busca de la seguridad perdida. Paidós: Madrid.

BENJAMÍN, W. (1967): “Tesis de filosofía de la historia”. Ensayos escogidos. Sur: Buenos Aires.

CASTELLS, M. (2019): “Seminário Comunicação, Política e Democracia”. FGV (16 de julio): Río de Janeiro. Recuperado de: https://www.youtube.com/watch?v=I4cizUYfZ18

CASTELLS, M. (2018a): “Vuelve el nazismo (1)” La Vanguardia (3 de junio): Barcelona. Recuperado de:

https://www.lavanguardia.com/opinion/20180630/45489927628/vuelve-el-nazismo1.html

CASTELLS, M. (2018b): "El talón de Aquiles: la identidad ambivalente de Europa".

Castells, M. (eds.): La crisis de Europa. Alianza editorial: Madrid.

CASTELLS, M. (2018c): “De la crisis al movimiento social y al cambio político: Podemos en España”. Castells, M. (eds.): La crisis de Europa. Alianza editorial: Madrid.

CASTELLS, M. (2017a): Ruptura. La crisis de la democracia liberal. Alianza: Madrid.

Castells, M. (2017b): “Trump contra el mundo" La Vanguardia (3 de junio): Barcelona. Recuperado de:

https://www.lavanguardia.com/opinion/20170603/423150817561/trump-contra-elmundo.html

CASTELLS, M. (2014): “Desarrollo insostenible en un planeta urbanizado: la crisis de la cultura urbana en las metrópolis del siglo XXI". Premio Internacional CGLU - Ciudad de México - Cultura 21 (noviembre): México. Recuperado de: http://agenda21culture.net/sites/default/files/files/pages/awardpages/art_MC2_SPA.pdf 
CARDOSO, G.; ACCORNERO, G.; LAPA, T. Y AZEVEDO, J. (2018): "Movimientos sociales, participación y crisis en Europa. Castells et al. (eds.). Las crisis de Europa. Alianza: Madrid

COLLIER, P. (2018): "Europa y los refugiados: una tragedia rayana en la farsa". Castells et al. (eds.). Las crisis de Europa. Alianza: Madrid

FANON, F. (2001 [1961]): Los condenados de la tierra. FCE: México.

FINCHELSTEIN, F. (2019). Del fascismo al populismo en la historia. Taurus: Madrid.

GERMANÁ, C. (2019): "Más allá de la crisis. Horizontes desde una perspectiva descolonial”. Discursos del Sur, № 3, pp. 77-94. UNMSM: Lima.

GERMANÁ, C. (2010): “Una epistemología otra: El proyecto de Aníbal Quijano”. Nomadas, № 32, pp. 211-221.Universidad Central: Bogotá.

JALIFE, A. (2019a): “El migrante Triángulo del Norte: cambio climático, café, violencia y evangelismo". SputniK Mundo (13 de junio). Recuperado de:

https://mundo.sputniknews.com/firmas/201906131087617900-migrante triangulonorte/

JALIFE, A. (2019b): “Agroindustria y Paradojas del Campo Desahuciado". Universidad de Chapingo (17 de mayo). Recuperado de:

https://www.youtube.com/watch?v=w7nyqNffB3E\&t=3666s

JALIFE, A. (2017): Trump y el supremacismo blanco. Palestinización de los mexicanos. Orfila: México.

JONES, M. (2013): Antiguas y nuevas murallas de Lima. Espacio y subjetividad. Tesis de Maestría en sociología, UNMSM: Lima.

KLAREN, P. (1976): Formación de las haciendas azucareras y orígenes del APRA. IEP: Lima.

LACLAU, E. (2006): La razón populista. FCE: México.

LENIN, V. I. (1977 [1917]): El imperialismo, fase superior del capitalismo. Progreso: Moscú.

LYNCH, N. (2017): Populismo: ¿dictadura o democracia?. UNMSM. Lima.

MEJÍA, J. (2019): “Nuevo horizonte de sentido histórico, crisis de la modernidad y movimientos de la sociedad. El legado teórico de Aníbal Quijano”. Discursos del Sur, № 3, pp. 95-109. UNMSM: Lima.

MEJÍA, J. (2016): “Cultura y dignidad en América Latina. Descolonialidad de la desigualdad social”. Investigaciones Sociales, № 37, pp. 315-324. UNMSM: Lima. 
MEJÍA, J. (2014): “Colonialidad y des/colonialidad en América Latina. Elementos teóricos". Aníbal Quijano: Des/colonialidad y bien vivir. Un nuevo debate en América Latina. Editorial URP: Lima.

MIGNOLO, W. (2006): "El giro epistémico descolonial: la contribución de Aimé Césaire a la geopolítica y biopolítica del conocimiento". Aimé Césaire: Discurso sobre el colonialismo. Akal: Madrid.

MIGNOLO, W. (2003): Historias locales/diseños globales. Colonialidad, conocimientos subalternos y pensamiento fronterizo. Akal: Madrid.

MOLINARI, T. (2017): Dictadura, cultura autoritaria y conflicto político en el Perú (19361939). UNMSM: Lima.

OIT (2013): Migración laboral internacional. Un enfoque basado en los derechos. Plaza y Valdés: Madrid.

PALERMO, Z. y QUINTERO, P. (2014): Aníbal Quijano. Textos de fundación, Ediciones del Signo: Buenos Aires.

PIKETTY, T. (2015). El capital del siglo XXI. FCE: México.

QUIJANO, A. (ed.) (2014): Des/colonialidad y bien vivir. Un nuevo debate en América Latina. Editorial URP: Lima.

QUIJANO, A, (1998): “Populismo y fujimorismo”. Burbano de Lara, F. (Editor): El fantasma del populismo: Aproximación a un tema (siempre) actual. Nueva Sociedad: Caracas.

ROSAS, V. (2019): "Sende her back": el discurso de odio de Trunp. El Comercio, № 90488, 20 de julio, Lima.

RUIZ, A. y BRUNET, P. (2018): Levantando muros. Políticas del miedo y securitización en la Unión Europea. Resumen Ejecutivo. Centre d' Estudis Delàs per la Pau: Barcelona. Recuperado de:

http://www.centredelas.org/images/INFORMES_i_altres_PDF/informe35_RE_Levantan doMuros_CAST.pdf

SANTOS, Boaventura de Sousa (2010) Para descolonizar occidente. Más alla del pensamiento abismal. CLACSO - Prometeo Libros: Buenos Aires.

Sennett, R. (1997): Carne y piedra. El cuerpo y la ciudad en la civilización occidental. Alianza: Madrid.

STANDING, G. (2016). "El precariado y la lucha de clases". Sin Permiso: república y socialismo también para el siglo XXI, №15 (Segunda época), pp. 87-102.

STANDING, G. (2013) El precariado una nueva clase social. Pasado y Presente: Barcelona. 
TAZÓN, S. (2008): Apartheid y Estado. Desigualdad ante la ley y fragmentación de la población y el territorio. Tesis Doctoral, Universidad de Zaragoza: Zaragoza.

TOURAINE, A (2016): El fin de las sociedades. FCE: México.

ROSAS, V. (2019): "Sende her back": el discurso de odio de Trump. El Comercio, № 90488, 20 de julio, Lima.

WIEVIORKA, M. (2018). "Europa frente al mal: xenofobia, racismo, antisimetismo y terrorismo". Castells et al.(eds.). Las crisis de Europa. Alianza: Madrid. 